\title{
The effect of the use of a new type of partogram on the cesarean section rates
}

\author{
Georgios Vlachos ${ }^{1}$, Panagiotis Tsikouras ${ }^{1}$, Bachar Manav ${ }^{1}$, Grigorios Trypsianis ${ }^{1}$, Vasileios Liberis ${ }^{1}$, \\ Sakellarios Karpathios ${ }^{2}$, Georgios Galazios ${ }^{1}$ \\ 'Department of Obstetrics and Gynecology, Democritus University of Thrace, Alexandroupolis, Greece \\ ${ }^{2}$ Department of Obstetrics and Gynecology, Emeritus Assistant Professor, $1^{\text {st }}$ University \\ Alexandra Hospital, Athens, Greece
}

\section{Abstract}

Objective: To assess the contribution of a new type of partogram, used in labor monitoring, in caesarean section rates.

Material and Methods: The study included term singleton uncomplicated pregnancies divided into two groups. Two types of partogram were used in labor monitoring. In the first group, the classical WHO partogram (A) was used. In the second group, a new type of partogram, in which cervical dilatation and the position of descending head (B) (one line) were estimated and reported, was used. The labor duration and caesarean section rates were calculated and compared in the two groups.

Results: A statistically significant decrease in labor duration (from the initiation of the active phase of labor to the delivery time) (dt1 + dt $2+\mathrm{dt} 3$ ) ( $<<0.001$, A: median: $318.4 \pm 10.4 \mathrm{~min}, \mathrm{~B}: 246.56 \pm 8.28 \mathrm{~min})$ and in caesarean section rates was noted ( $\mathrm{<}<0.001, \mathrm{~A}: 89 \mathrm{vs}$ B: 49).

Conclusion: The new type of partogram seems to have potential benefits such as reducing the incidence of prolonged labor and decreasing the caesarean section rates. (J Turk Ger Gynecol Assoc 2015; 16: 145-8)

Keywords: New type of partogram, caesarean section rate, labor management

Received: 18 April, $2015 \quad$ Accepted: 16 July, $2015 \quad$ Available Online Date: 06 August, 2015

\section{Introduction}

Recently, the caesarean section (CS) rates have dramatically increased worldwide. However, there is no clear evidence of a simultaneous decrease in maternal or perinatal morbidity or mortality $(1,2)$. The process of labor is associated with both maternal and fetal potential risks, regardless of the mode of delivery $(3,4)$. There are various CS indications that aim to reduce the maternal/fetal risks (5-7). However, most of the caesarean deliveries are performed because of relative indications, according to which the maternal/fetal risks are thought to be relatively less in CS compared with vaginal delivery (8). In the developing countries, prolonged labor is one of the most frequent causes of maternal mortality and is generally related to cephalopelvic disproportion and cervical dystocia (9). An early detection of the abnormal progress of labor was shown to prevent prolonged labor; reduce the risk of postpartum hemorrhage; and eliminate the obstructed labor, uterine rupture, and perinatal fetal asphyxia cases and admissions to the intensive neonatal care unit (10). The partogram is a labor graphic record of the progress of the first stage of labor combined with cervical dilatation and descent of head and labor duration (11). The aim of this study was to investigate the value of the use of a new type of partogram and compare it with the classical partogram in reducing the CS rates.

\section{Material and Methods}

This retrospective study included the labor management of 478 term, singleton pregnancies, and the following deliveries were conducted at the University Hospital of Alexandroupolis, Greece. The study had the approval of the ethics committee, and all participants gave their informed consent to this study.

In this retrospective study, partograms of the cases with the following criteria were included in the study: cervical dilatation not more than $6 \mathrm{~cm}$, singleton pregnancies, gestation of at least 37 completed weeks, cephalic presentation, no use of oxytocin in the first stage of labor, and absence of additional complications. We compared the efficacy of the two types of partograms during labor. A total of 478 maternity records were audited retrospectively: 340 (71.2\%) spontaneous vaginal deliveries and 138 (28.8\%) caesarean births. The exclusion criteria were hypertension, antepartum hemorrhage, and post term pregnancies. Cord blood $\mathrm{pH}$ measurement was not performed, and none of the women received epidural analgesia.

The study population was divided into two groups according to the type of partogram used during labor monitoring. The two types of partograms used were as follows:

1) Fisher partogram, with one -hour two lines: cervical dilatation and actions line evaluated every one hour. 
Table 1. Characteristics of women according to the partogram

\begin{tabular}{|l|c|c|c|}
\hline \multicolumn{2}{|c|}{ Fischer } & $\begin{array}{c}\text { New type } \\
\text { of partogram }\end{array}$ & p \\
\hline Number of women & 89 & 49 & \\
\hline $\begin{array}{l}\text { Age (years; } \\
\text { mean } \pm \text { SD) }\end{array}$ & $29.10 \pm 3.15$ & $29.56 \pm 3.68$ & 0.659 \\
\hline Parity, no (\%) & $42(80.0 \%)$ & $38(76.0 \%)$ & 0.678 \\
\hline \multicolumn{1}{|c|}{ Nulliparous } & $10(20.0 \%)$ & $12(24.0 \%)$ & \\
\hline \multicolumn{1}{|c|}{ Multiparous } & $39.23 \pm 0.86$ & $39.18 \pm 0.87$ & 0.791 \\
\hline $\begin{array}{l}\text { Gestation (weeks; } \\
\text { mean } \pm \text { SD) }\end{array}$ & $3424.17 \pm 328.29$ & $3403.40 \pm 328.63$ & 0.817 \\
\hline $\begin{array}{l}\text { Birth weight } \\
\text { (g; mean } \pm \text { SD) }\end{array}$ & 9 & 9 & 1.000 \\
\hline $\begin{array}{l}\text { APGAR at 1 min } \\
\text { (mean } \pm \text { SD) }\end{array}$ & 10 & 10 & 1.000 \\
\hline $\begin{array}{l}\text { APGAR at 5 min } \\
\text { (mean } \pm \text { SD) }\end{array}$ & & & \\
\hline
\end{tabular}

2) New type of partogram, with one line depending on three parameters, i.e., cervical dilatation, actions, and fetal head descent line. The first stage of labor was divided into the latent phase and the active phase. The latent phase was defined as the time from the first cervical ripening agent until cervical dilatation reached $3 \mathrm{~cm}$, accompanied by the presence of two or more uterine contractions in $10 \mathrm{~min}$, each lasting $20 \mathrm{~s}$ or more and is followed by the gradual shortening of the cervical length. The active phase of labor was defined as the time from the cervical dilation of $\geq 3 \mathrm{~cm}$ [until complete cervical dilatation $(10 \mathrm{~cm})]$ and characterized by the presence of painful regular contractions (every $5 \mathrm{~min}$ or less, lasting more than $20 \mathrm{~s}$ ) and a cervical dilatation rate of at least $1 \mathrm{~cm} / \mathrm{h}$. Amniotomy was performed in cases of slow labor progress or an arrest of cervical dilatation over $1 \mathrm{~h}$. The duration of the first stage of labor was defined as the time required to reach a full cervical dilatation. The progress of labor was correlated with the cervical dilatation and descent of the fetal head. The descent of the fetal head was measured by vaginal examination, but it did not take place until the cervix reached a dilatation of $7 \mathrm{~cm}$. A deceleration phase seemed to be present at the end of the active phase of labor (full cervical dilatation). The second stage was defined as the time from the first active expulsion efforts to delivery. In each group, the following parameters were recorded: cervical dilatation (at least once every $1 \mathrm{~h}$ ), fetal heart rate, blood pressure, maternal temperature (hourly), and postnatal fetal outcome. The mean values of these parameters were used to construct the partograms. The following parameters were studied and were noted in the partogram for both group A and group B as an alert line: characteristics of women and time intervals (in min) from the time of decision to the time of intervention.

\section{Results}

From January 2005 to December 2010, a total number of 478 pregnant women who met the inclusion criteria of our study attended the Obstetric Department of our Hospital. The mater- nity records were checked retrospectively: 340 women (71.2\%) had spontaneous vaginal deliveries and 138 women (28.8\%) underwent emergency CS. The partogram of 200 grand multipara women (mean 2 previous deliveries) were analyzed according to the Fisher partogram (total 69) and the new type of partogram (total 131) and were compared with the partogram of nulliparous women (total 278) who either had the Fisher partogram (total 112) or the new type of partogram (total 165) (Tables 1, 2). The full-term pregnancies were normal, and the vaginal deliveries were spontaneous and non-instrumental. In total, 171 nulliparous and 169 multiparous women had a normal vaginal delivery, whereas 107 nulliparous and 31 multiparous women underwent CS (Table 1). The deviation of maternal age $(p=0.659)$, parity $(p=0.678)$, and gestational week $(p=0.791)$ between the two groups was not statistically significant (Table 1). The recorded values of fetal heart rate, blood pressure, and maternal temperature were within normal limits. No cases of neonatal mortality were recorded. The mean birth weight was similar in both groups $(p=0.187)$ (Table 1). The condition of the neonates was assessed using the APGAR score because there were no facilities for cord blood sampling. APGAR scores at 1 and 5 min after labor recorded in all studied participants were also similar between the two groups $(p=1.00)$ in the cesarean section group (Table 1). On the other hand, in the cesarean section group, the overall time from admission to the hospital until delivery was longer (by $19.3 \%$ ) in the participants whose labor progress was evaluated with the partogram B $(512.00 \pm 16.61 \mathrm{~min}$ vs. $429.17 \pm 15.34 \mathrm{~min})$ than those using partogram $A$ [ $p=0.001 ; 95 \%$ confidence interval (CI) of the difference, 33.97-131.69 min] (Table 2).

\section{Discussion}

According to our findings, the new type of partogram is a great tool in labor management. It contributes to the early detection of obstructed labor. In addition, compared with the classical partogram, it leads to earlier decision making in labor management and is shown to reduce the section rates. The worldwide increase in caesarean section rates is due to indications such as labor abnormalities, fetal distress maternal age, and parity, which are often over-diagnosed (12-14). The partogram may be a useful tool in increasing the quality of all observations on the fetus and mother in labor. It may lead to early problem detection and has many potential benefits on the active management of labor $(15,10)$. However, the use of a partogram is controversial, particularly in elective cesarean section cases, in which no advantages are observed because there is no labor (16). Active management, opposed to expectant management, has reduced the prolonged labor incidence and the caesarean section rates (10). The use of the partogram reduces the risk of prolonged labor, cesarean sections, and perinatal mortality (17-20). The documentation of the partogram includes the administration of oxytocin and procedures such as amniotomy (18). In the classical Fisher partogram, cervical dilatation and action line are the recorded parameters of the progress of labor. It consists of two straight diagonal parallel lines, where the action line is parallel and at the right of the alert line, but the fetal head descent is not included (21). The alert line drawn from 
Table 2. Time intervals (in min; expressed as mean \pm standard error) and caesarean section rates in two groups

\begin{tabular}{|l|c|c|c|c|}
\hline & Fischer & $\begin{array}{c}\text { New type } \\
\text { of partogram }\end{array}$ & $\begin{array}{c}\text { p5\% CI } \\
\text { of the difference }\end{array}$ \\
\hline Start of active phase - Labor & $344.50 \pm 12.80$ & $380.50 \pm 15.19$ & 0.074 & $-79.79-7.79$ \\
\hline Time of entrance in the hospital - Labor & $429.17 \pm 15.34$ & $512.00 \pm 16.61$ & 0.001 & $-131.69-33.97$ \\
\hline Caesarean section rate & $89 / 478(18.69 \%)$ & $49 / 478(10.25 \%)$ & 0.001 & $-8.3436-8.5124$ \\
\hline Cl: confidence interval & &
\end{tabular}

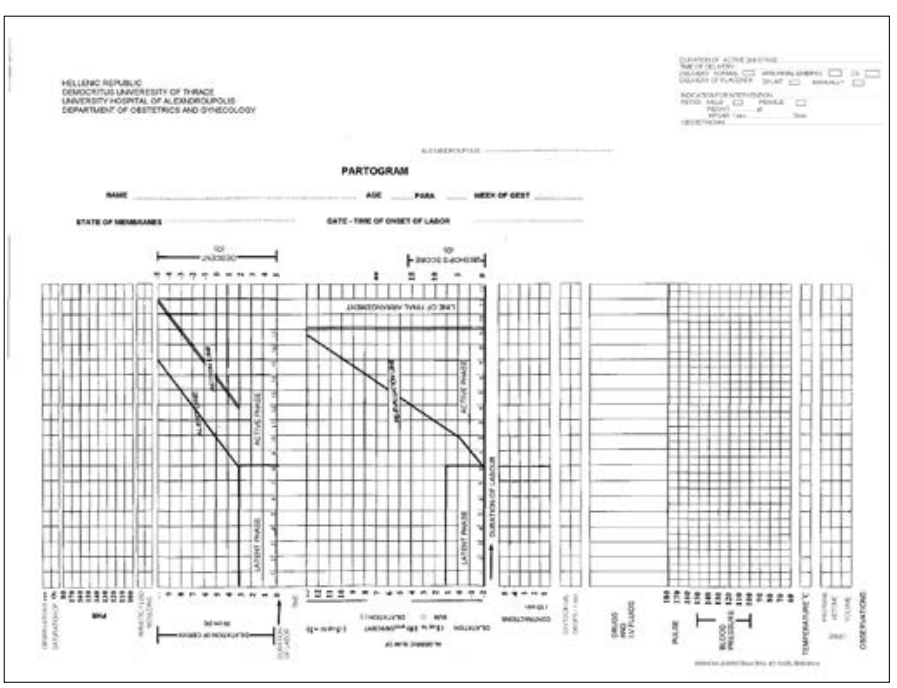

Figure 1. New type of partogram

$3 \mathrm{~cm}$ to $10 \mathrm{~cm}$ represents the dilatation rate. The action line is drawn in the right of the alert line and shows if cervical dilatation is altered. It is known that cervical dilatation is a critical assessment and one of the main reasons of prolonged labor. In the new partogram under study, the alert line is crossed only once, and it is included as part of the single graphic line evaluation of labor progress (Figure 1). An early decision about the appropriate management to overcome the labor delay is possible with the use of the new type of partogram with only one graphic line (22). The wide variation in the published records of labor observation suggests that midwives and some obstetricians prioritized cervical dilatation over the other parameters (21). It is notable that the partogram and particularly the new partogram can only be used by health workers with adequate experience in midwifery and who are responsible and authorized to observe and conduct normal labor, perform vaginal examination, assess cervical dilatation and fetal head descent accurately, and immediately note cervical dilatation and head descent on a graph against time. The results of our study confirm that the fetal head descent is an important labor progress parameter when it comes to decision making concerning the delivery mode. The failure of descent of the presenting part during the first stage of labor in addition to the arrest of cervical dilatation was associated with high cesarean section rates. However, the slow head descent is caused by pelvic floor physiological changes and is not exclusively due to cephalopelvic disproportion, particularly in multiparas (23). The fetal condition intrapartum, to achieve satisfying fetal outcome, is closely monitored on the partogram by the regular observation of the fetal heart rate, liquor, and the molding of the fetal skull bones (24). The substandard intrapartum fetal monitoring is strongly associated with poor fetal outcome $(p<0.001)(24)$. Although partograms have been described and used since the early 1970s, it is still not used worldwide (9). The reasons may be the lack of leaders of the professional partogram use and the existence of various partograms, which results in the new users following conflicting guidelines. We believe that further studies of the new type of partogram should be conducted to investigate the association of this functioning referral system with perinatal results and caesarean frequency rates. According to our opinion, the introduction of partograms in labor monitoring accompanied by a program of training in its use is of great importance.

Ethics Committee Approval: Ethics committee approval was received for this study from the ethics committee of General Hospital of Xanthi and University Hospital of Alexandroupolis.

Informed Consent: Written informed consent was obtained from patients who participated in this study.

Peer-review: Externally peer-reviewed.

Author Contributions: Concept - S.K., G.G., P.T.; Design - G.V., P.T., G.G.; Supervision - G.G., P.T.; Resource - G.G., P.T.; Materials - G.V., P.T.; Data Collection and/or Processing - G.V., P.T.; Analysis and/or Interpretation - G.T., P.T.; Literature Search - G.V., P.T., B.M.; Writing - G.V., P.T., B.M.; Critical Reviews - V.L., G.G.

Conflict of Interest: No conflict of interest was declared by the authors.

Financial Disclosure: The authors declared that this study has received no financial support.

\section{References}

1. Hamilton BE, Hoyert DL, Martin JA, Strobino DM, Guyer B. Pediatrics 2013; 131: 548-58. [CrossRef]

2. Gregory KD, Jackson S, Korst L, Fridman M. Cesarean versus vaginal delivery: whose risks? Whose benefits? Am J Perinatol 2012; 29: 7-18. [CrossRef]

3. Guise JM, Eden K, Emeis C, Denman MA, Marshall N, Fu RR, et al. Vaginal birth after cesarean: new insights. Evid Rep Technol Assess (Full Rep) 2010; 191: 1-397. [CrossRef]

4. Clark SL, Belfort MA, Dildy GA, Herbst MA, Meyers JA, Hankins GD. Maternal death in the 21st century: causes, prevention, and relationship to cesarean delivery. Am J Obstet Gynecol 2008; 199: 36.e1-5; discussion 91-2. e7-11.

5. Chamberlain G. What is the correct caesarean section rate? Br J Obstet Gynaecol 1993; 100: 403-4. [CrossRef]

6. Liu Y, Li G, Chen Y, Wang X, Ruan Y, Zou L, Zhang W. A descriptive analysis of the indications for caesarean section in mainland China. BMC Pregnancy Childbirth 2014; 14: 410. [CrossRef] 
7. Deng W, Klemetti R, Long Q, Wu Z, Duan C, Zhang WH, et al. Cesarean section in Shanghai: women's or healthcare provider's preferences? BMC Pregnancy Childbirth 2014; 14: 285. [CrossRef]

8. Dabbas M, Al-Sumadi A. Cesarean section rate: much room for reduction. Clin Exp Obstet Gynecol. 2007; 34: 146-8.

9. Ogwang S, Karyabakabo Z, Rutebemberwa E. Assessment of partogram use during labour in Rujumbura Health Sub District, Rukungiri District, Uganda. Afr Health Sci 2009; 9 (Suppl 1): 27-34.

10. Van Bogaert LJ. The partogram's result and neonatal outcome. J Obstet Gynaecol 2006; 26: 321-4. [CrossRef]

11. Bosse G, Massawe S, Jahn A. The partograph in daily practice: it's quality that matters. Int J Gynaecol Obstet 2002; 77: 243-4. [CrossRef]

12. Lagrew DC, Bush MC, McKeown AM, Lagrew NG. Emergent (crash) cesarean delivery: indications and outcomes. Am J Obstet Gynecol 2006; 194: 1638-43; discussion 1643. [CrossRef]

13. Ryan K, Schnatz P, Greene J, Curry S. Change in cesarean section rate as a reflection of the present malpractice crisis. Conn Med 2005; 69: 139-41.

14. Penn Z, Ghaem-Maghami S. Indications for caesarean section. Best Pract Res Clin Obstet Gynaecol 2001; 15: 1-15. [CrossRef]

15. Fatusi AO, Makinde ON, Adeyemi AB, Orji EO, Onwudiegwu U. Evaluation of health workers' training in use of the partogram. Int J Gynaecol Obstet 2008; 100: 41-4. [CrossRef]

16. Leanza V, Leanza G, Monte S. A didactic protocol for labour and delivery: the partogram. Minerva Ginecol 2011; 63: 325-32.
17. Zhang J, Landy HJ, Branch DW, Burkman R, Haberman S, Gregory $\mathrm{KD}$, et al. Contemporary patterns of spontaneous labor with normal neonatal outcomes. Obstet Gynecol 2010; 116: 1281-7. [CrossRef]

18. Orhue A, Aziken ME, Osemwenkha AP. Partograph as a tool for team work management of spontaneous labor. Niger J Clin Pract 2012; 15: 1-8. [CrossRef]

19. Kidanto HL, Massawe SN, Nystrom L, Lindmark G. Analysis of perinatal mortality at a teaching hospital in Dar es Salaam, Tanzania, 1999-2003. Afr J Reprod Health 2006; 10: 72-80 [CrossRef]

20. Hofmeyr GJ. Obstructed labor: using better technologies to reduce mortality. Int J Gynaecol Obstet 2004; 85 (Suppl 1): 62-72. [CrossRef]

21. Mathews JE, Rajaratnam A, George A, Mathai M. Comparison of two World Health Organization partographs. Int J Gynaecol Obstet 2007; 96: 147-50. [CrossRef]

22. Galazios G, Tica V, Vrachnis N, Vlachos G, Zervoudis S, Ceausu I, et al. Assessment of labor using a new type partogram compared to the classical Fisher partogram. J Matern Fetal Neonatal Med 2015; 28: 82-7. [CrossRef]

23. Juntunen K, Kirkinen P. Partogram of a grand multipara: different descent slope compared with an ordinary parturient. Perinat Med 1994; 22: 213-8 [CrossRef]

24. Sallam HN, Abdel-Dayem A, Sakr RA, Sallam A, Loutfy I. Mathematical relationships between uterine contractions, cervical dilatation, descent and rotation in spontaneous vertex deliveries. Int J Gynaecol Obstet 1999; 64: 135-9. [CrossRef] 